\title{
Tomislav Zelić, Zaneta Sambunjak, Paul Michael Lützeler, Hermann Broch im Kontext der Donaumonarchie
}

\section{Christine Mondon}

\section{CpenEdition}

\section{Journals}

Édition électronique

URL : https://journals.openedition.org/austriaca/919

DOI : 10.4000/austriaca.919

ISSN : 2729-0603

\section{Éditeur}

Presses universitaires de Rouen et du Havre

\section{Édition imprimée}

Date de publication : 1 décembre 2019

Pagination : 284-286

ISBN : 979-10-240-1454-8

ISSN : 0396-4590

\section{Référence électronique}

Christine Mondon, « Tomislav Zelić, Zaneta Sambunjak, Paul Michael Lützeler, Hermann Broch im Kontext der Donaumonarchie », Austriaca [En ligne], 88-89 | 2019, mis en ligne le 01 juillet 2020, consulté le 24 octobre 2022. URL : http://journals.openedition.org/austriaca/919 ; DOI : https:// doi.org/10.4000/austriaca.919

Ce document a été généré automatiquement le 24 octobre 2022

Tous droits réservés 


\title{
Tomislav Zelić, Zaneta Sambunjak, Paul Michael Lützeler, Hermann Broch im Kontext der Donaumonarchie
}

\author{
Christine Mondon
}

\section{RÉFÉRENCE}

Tomislav Zelić, Zaneta Sambunjak, Paul Michael Lützeler (dir.), Hermann Broch im Kontext der Donaumonarchie, Tübingen, Stauffenburg, «Stauffenburg Kolloquium », vol. 87, 2017, 260 p., ISBN : 978-3-95809-326-3.

1 Édité par Tomislav Zelić, Zaneta Sambunjak et Paul Michael Lützeler, spécialiste, éditeur et biographe de Broch, cet ouvrage, qui est le fruit d'une journée d'étude organisée début septembre 2016 à l'université de Zadar en Croatie, se propose d'analyser l'œuvre de Hermann Broch dans le contexte de la monarchie habsbourgeoise à la fin du XIX $x^{\mathrm{e}}$ siècle et au début du Xx $\mathrm{x}^{\mathrm{e}}$ siècle.

2 La fragilité, les crises et la chute de l'Empire ont servi de modèle à Broch dans son diagnostic du déclin des valeurs. Barbara Mahlmann-Bauer s'interroge sur l'image de l'Empire dans les ouvrages de Musil (L'Homme sans qualités), de Joseph Roth (La Marche de Radetzky), de Ludwig Winder (Le Successeur au trône), de Broch (Les Somnambules) et dans l'essai de Broch Hofmannsthal et son époque. Ce que Musil a appelé la Cacanie, Broch l'a appelé «l'apocalypse joyeuse ». Après 1848, mais surtout après 1873, l'État autrichien ressemble à un véritable squelette, comme l'écrit Broch dans l'essai sur Hofmannsthal: "Ce qui subsistait encore de l'État autrichien c'était le fantôme, le squelette d'une théorie à laquelle personne ne croyait plus. / L'État était une chose et les activités politiques dont il était le théâtre en étaient une autre. Entre les deux, il y avait une espèce de couche isolante impénétrable qui, manifestement, rendait abstrait chacun d'eux » (p. 95-96 et 162). Dans cet essai, Broch donne une image pathétique de l'Empereur : "politique d'orientation abstraite ", mené par celui qui a un «goût [...] 
pour l'abstraction » (p. 89 et 156); «Plus François Joseph ${ }^{\text {er }}$ vieillit, plus il plongea dans le vide de sa mission [...] et [...] devait supporter sa part d'isolement abstrait » (p. 97 et 163).

3 De son côté, Monika Ritzer analyse l'essai sur Hofmannsthal dans le sens d'une « utopie rétrospective» (p.68) et Lützeler le lit comme un "auto-entretien» fictif où transparaît l'amour conflictuel de Broch vis-à-vis de sa ville natale (p. 92). À partir de là, Paul Michael Lützeler approfondit l'écriture autobiographique chez Broch qui n'a pas écrit d'« autobiographie » à proprement parler, mais a été un épistolier fécond et a écrit deux textes durant son exil aux États-Unis, Autobiographie psychique (1942), où il dévoile ses contradictions et sa nature conflictuelle, et Autobiographie comme programme de travail, centrée davantage sur l'œuvre.

Dans l'essai sur Hofmannsthal, Broch souligne le déséquilibre entre les nationalités qu'il considère comme une " création abstraite » (p. 95 et 161). La question du judaïsme mérite donc d'être évoquée, en particulier la situation du Juif assimilé (Lützeler, p. 91) à Vienne sous François-Joseph.

5 Bien que les romans de Broch ne se situent pas à Vienne, l'atmosphère viennoise est perceptible (Claudia Liebrand, Gabriela Ràcz), y compris dans Les Somnambules (Sarah McGaughey). Le penchant pour l'auto-analyse (Lützeler, Bernhard Fetz) ainsi que le diagnostic des crises de l'identité (Ritzer, Zelić, p. 257) ancrent l'auteur dans le contexte originel de sa Vienne natale. Vienne, le berceau de son œuvre, a nourri sa pensée, en dépit de l'éloignement, de l'exil sans retour aux États-Unis où il écrit entre autres $L a$ Mort de Virgile (Renato Cristin) et sa théorie des masses (Wolfgang Müller-Funk).

6 L'intérêt de Broch pour l'Italie sort des sentiers battus (Friedrich Vollhardt) et la comparaison avec Italo Svevo (La Conscience de Zeno), l'auteur natif de Trieste, mérite d'être soulignée (Fetz), ne serait-ce que pour illustrer ce grand Empire habsbourgeois qui incluait une partie de l'Italie.

7 Qui est Broch, finalement ? Un « écrivain malgré lui » selon Hannah Arendt en 1949 ou bien un «philosophe malgré lui», selon les mots de son fils? Ou encore un psychanalyste, un historien, un sociologue? L'œuvre de Broch sublime toutes ces alternatives, car il a l'intuition profonde de l'œuvre absolue qu'il porte en lui.

8 Cet ouvrage a le mérite d'approfondir la relation qui unit Broch à l'Empire des Habsbourg et à sa ville natale, entre ombre et lumière. 